\title{
REFORMA PROCESAL CIVIL Y RECURSO \\ EXTRAORDINARIO. LA DISCUSIÓN PENDIENTE. \\ COMENTARIOS AL BOLETÍN No 8197-07
}

Civil Procedure Reform and extraordinary remedy. The

SLOPE ARGUMENT. COMMENTS ON Bulletin No 8197-07

RÉFORME À LA PROCÉDURE CIVILE ET LE POURVOI

EXTRAORDinaIRE. LE DÉBAT EN ATTENDANT. COMMENTAIRES AU

BuLLETIN No 8197-07

Pablo Cornejo Aguilera*

\section{INTRODUCCIÓN}

El pasado 9 de mayo de 2014, por la unanimidad de los votos de los parlamentarios presentes, la Sala de la Cámara de Diputados aprobó en primer trámite constitucional el Proyecto de Código Procesal Civil ${ }^{1}$, correspondiendo ahora la revisión del proyecto de ley por parte de la Comisión de Constitución, Legislación, Justicia y Reglamento del Senado. Sin embargo, la forma en que se produjo esta aprobación no puede dejar de llamar la atención, toda vez que el proyecto que ingresó al Senado presenta importantes diferencias con aquel que fue primitivamente sometido a discusión por el Ejecutivo. En este orden, resulta particularmente llamativa la eliminación de aquellas materias que más controversias habían generado en la comunidad jurídica nacional ${ }^{2-3}$, como son el Libro IV del

\footnotetext{
* Abogado. Licenciado en Ciencias Jurídicas y Sociales de la Universidad de Chile. Master, Droit international et comparé, Universidad de Lausanne, Suiza. Profesor Invitado Departamento de Derecho Privado, Facultad de Derecho de la Universidad de Chile. Correo electrónico: pcornejo@derecho.uchile.cl.

Mis agradecimientos a la profesora María José Arancibia, por sus valiosos comentarios y su colaboración en la edición de este comentario.

${ }^{1}$ En adelante, indistintamente el Proyecto o PCPC.

${ }^{2}$ Para una revisión general de estas críticas, puede verse el documento preparado por académicos del Departamento de Derecho Privado de la Facultad de Derecho de la Universidad de Chile. v. VV.AA. (2012). "Comentarios al proyecto de nuevo Código Procesal Civil". Gaceta Jurídica, No 388, pp. 7-34.

${ }^{3}$ Adicionalmente, debe tenerse presente que antes la Comisión de Constitución de la Cámara ya había eliminado otro de los puntos más controvertidos del Proyecto, las denominadas "cargas dinámicas de la prueba", que fueron reemplazadas por un perfeccionamiento de los mecanismos procesales de colaboración en la actividad probatoria. Sobre esta discusión, v. Arancibia Obrador, María José (2009-2012). "Cargas probatorias dinámicas desde el punto de vista del Derecho civil”. Temas de Derecho, Años XXIV-XXVII, enero 2009 - diciembre 2012, pp. 199-212; Bravo Hurtado, Pablo (2013). "La derrotabilidad de la carga
} 
Proyecto, cuyo procedimiento estaba estructurado en torno a la existencia de una nueva figura cuya posición institucional no se encontraba todavía bien definida -el oficial de ejecución-, y el recurso extraordinario, que pretendía reemplazar el actual recurso de casación en el fondo como mecanismo de acceso a la Corte Suprema, por un nuevo medio de impugnación que se presentaba esencialmente como una herramienta de promoción del interés general, que operaría a través del desarrollo de una jurisprudencia selectiva.

¿Significa la eliminación del recurso extraordinario que debamos mantener la casación como está actualmente contemplada en nuestro Código de Procedimiento Civil? Creemos que una negativa absoluta a revisar el sistema recursivo, conservando los actuales recursos de apelación, casación en la forma y casación en el fondo sin alteraciones, parece muy poco razonable en el contexto de la preparación de un nuevo Código Procesal Civil, máxime en circunstancias que se trata de una materia que tendrá un directo impacto sobre el valor que asignamos a las instancias previas de juzgamiento. En este sentido, si queremos realmente valorar la decisión que se ha adoptado por un juez de instancia, que toma conocimiento inmediato de los hechos y de las alegaciones de las partes, por medio de audiencias orales en las que ellas participan en un plano de igualdad, no debemos sino concebir la existencia de los recursos como una cuestión extraordinaria que, como diría el profesor Maturana, solamente resulta procedente a fin de impugnar las resoluciones que pongan término al procedimiento o que se pronuncien sobre una medida cautelar y siempre con el objetivo de velar por el respeto de los derechos de las partes y de la ley en la pronta y justa solución de los conflictos ${ }^{4}$.

Nos parece oportuno destacar que las discusiones que tienen lugar sobre el régimen recursivo excede el simple marco de la reforma en los procedimientos, para situarse en uno más bien político, referido a la manera como concebimos las relaciones que existen entre los órganos que integran el Poder Judicial, cuestión

\footnotetext{
de la prueba en la responsabilidad contractual: hacia la facilidad probatoria en Chile". Revista Chilena de Derecho Privado, No 21, pp. 13-46; Carvajal Ramírez, Patricio-Ignacio (2012). "Non liquet! Facilidad probatoria en el Proyecto de un nuevo Código Procesal Civil”. Revista Chilena de Derecho, Vol. 39, № 3, pp. 565-604; Palomo Veliz, Diego (2013). "Las cargas probatorias dinámicas: ¿ Es indispensable darse toda esta vuelta?". Ius et Praxis, año 19, № 2, pp. 447-464; Pinochet Cantwell, Francisco (2011). "Cargas dinámicas de la prueba: el modelo chileno. Algunos comentarios sobre la propuesta de regulación legal”. En: Justicia civil y comercial: Una reforma ¿Cercana?, Leturia Infante, Francisco (Edit.), Santiago: LyD Editores, pp. 309-338.

${ }^{4}$ Maturana Miquel, Cristián (2012). "Los recursos ante los tribunales colegiados en un procedimiento oral”. Revista de Derecho Procesal, Universidad de Chile, № 22, p. 419. Destacando las implicancias políticas de esta definición, señala el profesor Atria que "En un régimen republicano, el poder que ejerce el juez inferior no es un poder delegado por el superior. Un juez en un sistema republicano es independiente en un sentido en que un juez en un sistema monárquico no lo puede ser. El juez republicano no es un comisario o mandatario de nadie. Su función no es arbitrar las medidas necesarias para llevar a buen término su encargo o comisión, sino aplicar reglas. Por eso es que, tratándose de la jurisdicción, independencia y sujeción a la ley no alcanzan a ser dos caras de la misma moneda, porque son en sentido estricto la misma cosa". ATRIA LEMAîTRE, Fernando (2005). "Proceso civil". Revista de Derecho de la Universidad Adolfo Ibáñez, No 2, p. 259.
} 
que resulta particularmente importante cuando se trata de definir cuáles serán las vías de impugnación que permitirán a las partes acceder al órgano que se encuentra en su cúspide, nuestra Corte Suprema. ¿Cómo se relacionará este tribunal con los otros poderes del Estado? ¿La relación que tendrá con los otros tribunales, se insertará en un contexto de validación jerárquica, o sobre la base de otro criterio de validación? ¿Cuáles serán las funciones que le corresponderá desarrollar? Todas estas interrogantes dan cuenta de un hecho que nos parece innegable: la discusión sobre el recurso extraordinario no es valorativamente neutra, ni se puede abordar desde una perspectiva puramente técnica. Por el contrario, ella es profundamente política, y nos obliga a reflexionar sobre cuál es el modelo de Corte Suprema que deseamos para nuestro país ${ }^{6}$.

Finalmente, no puede dejar de considerarse que en esta discusión existe todavía un elemento adicional, que está dado por la posible tensión que se produce entre los valores que son promovidos en cada diseño de sistema recursivo. ¿El énfasis estará en la protección de los derechos de los justiciables, admitiéndose de una forma amplia el acceso a la Corte, o estará puesto en el desarrollo de ciertos fines públicos, como la creación de una jurisprudencia uniforme? ¿ ¿En estas funciones,

\footnotetext{
${ }^{5}$ Lo que equivale a preguntarse sobre cuáles son las razones que permiten justificar que sea en definitiva el criterio jurídico de la Corte Suprema el que deba primar cuando se trata de resolver un determinado conflicto. Sobre este punto, señala Taruffo que "En lo que respecta especificamente a la función de la Casación, es criticable la tendencia a acreditar la idea mediante la cual la Corte tendría una suerte de monopolio de la verdad en la interpretación de la ley, y que tal verdad es conseguida de modo 'objetivo', neutral y fundado sólo en razones lógicas. Si y en cuanto no se trate de una mera legitimación de la autoridad al estado puro (en cuyo caso no merecería ni siquiera ser discutida) esta imagen de la Casación es rechazada precisamente por lo que propone. La idea de que la nomofilaquia se incardina exclusivamente sobre una interpretación formalista de la ley, que las interpretaciones suministradas por la Corte son, por definición, 'exactas' y que, por lo demás, aquella no cumple con elegir valores en la interpretación de la ley, no está sólo privada de fundamento. Ella delinea una Corte que juega un rol estático y homogeneizante en el vértice del sistema: más que la nomofilaquia, una Corte de este género aseguraría un control burocrático y autoritario sobre la jurisprudencia; más que el custodio de la legalidad, ella sería el garante de la conservación y el obstáculo principal a la evolución del derecho y a su adaptación a las necesidades reales de justicia". TARUFFO, Michelle (2006). El vértice ambiguo. Ensayos sobre la casación civil. Monroy Palacios, Juan y Monroy Gálvez, Juan (Trads.), Lima: Palestra Editores, p. 123.

${ }^{6}$ Como ejemplo de este tipo de problemática, como destaca el profesor Atria, debe tenerse presente que en el modelo tradicional de la casación revolucionaria la Corte de Casación debía ser identificada como un mandatario del legislador, cuestión que obligaba a poner énfasis no en la independencia de este tribunal respecto de su mandante, sino en la que pueden tener los jueces inferiores respecto de este tribunal que nació a un costado del Poder Legislativo, cuestión que pretendía ser asegurada por medio de la exigencia del reenvío y la negación a la Corte de la competencia para dictar una sentencia de reemplazo. AtRIA (2005), pp. 253-254.

${ }^{7}$ Más aún, desde una estricta perspectiva de políticas públicas, se ha dicho que un correcto sistema recursivo no sólo tiene que ser plenamente consistente con los estándares del debido proceso, sino que adicionalmente tiene que estar constituido de manera eficiente, de modo que permita obtener los fines públicos que le son propios (particularmente, el uniformar la jurisprudencia generando información útil para decidir otros casos similares) al menor costo posible, procurando una focalización de los recursos públicos y una reducción de los costos privados. $v$. Vargas Viancos, Juan Enrique y Fuentes Maureira, Claudio (2011). "Régimen recursivo para la reforma a la justicia civil”. En: Justicia civil y comercial: Una reforma ¿Cercana?, LETURIA InFANTE, Francisco (Edit.), Santiago: LyD Editores, pp. 355-356.
} 
la Corte debe mirar preferentemente el interés general que existe en la creación de una jurisprudencia armónica, o debe mirar el interés particular de obtener la revisión de una sentencia que ocasiona un agravio? Ciertamente, en materia de acceso a la máxima judicatura nacional siempre existirá una tensión entre la vigencia del ius constitutionis y el resguardo del ius litigatoris. Como bien ha constatado el profesor BARROS, es evidente que a la medida que la pirámide se cierra en el organigrama judicial, es necesario racionar el acceso a los recursos. Esto crea dos interrogantes: quién será el encargado de controlar el acceso a la máxima judicatura y conforme a qué criterios. Sin embargo, sobre este último punto, creemos que debemos partir de una premisa básica: la necesidad de resolución a esta interrogante no autoriza a adoptar cualquier clase de criterio de selección de las causas que serán conocidas por el máximo tribunal. Solamente por vía ejemplar, un criterio de selección basado en la cuantía, como el previsto por algunas legislaciones comparadas, podría plantear importantes dificultades en nuestro Derecho, desde la perspectiva en que entendemos la igualdad ante la ley y el acceso a la justicia.

Creemos que el rechazo de la Sala de la Cámara a aprobar el recurso extraordinario en los términos del Proyecto debe ser concebido antes como invitación a discutir sobre cuál será el modelo que deberá incorporarse en el nuevo Código, que como un rechazo en sí a toda modificación de la normativa actualmente vigente. Por esta razón, el objetivo de este breve comentario, más que desarrollar en forma acabada ideas sobre cuáles deben ser los lineamientos que deben ser recogidos al regular esta institución, o que proponer una determinada regulación para el recurso que sustituya a la rechazada por la Cámara, será tratar de enunciar las principales cuestiones que deberán ser discutidas, haciendo explícitas ciertas interrogantes que demandan una decisión, siempre con un ánimo propositivo, buscando contribuir a un debate que ahora comienza.

\section{1. ¿CuÁl es la situación actual?}

La cuestión sobre cuáles deben ser las materias de que conozca la Corte Suprema, y por consiguiente, sobre cuál debe ser la función que desarrolle este máximo tribunal, ha ocupado desde antiguo a la doctrina chilena, no habiendo sido un asunto completamente resuelto con la introducción del recurso de casación en el Código de $1902^{8}$, principalmente porque junto a éste continuaría perviviendo por largo tiempo el recurso de queja, conocido por la Corte en virtud de las facultades disciplinarias que ejerce sobre los tribunales inferiores ${ }^{9}$. Precisamente, y si

\footnotetext{
${ }^{8}$ Para una completa revisión de las cuestiones políticas que se suscitaron con ocasión de los diversos proyectos de recurso de casación, y particularmente las críticas de los liberales reflejadas en las exposiciones de don José Victorino Lastarria, v. Atria (2005), pp. 259 y ss. v. también, Tavolari Oliveros, Raúl (1999). Recurso de casación y queja. Nuevo régimen. Santiago: LexisNexis, pp. 31-35.

${ }^{9}$ Para un breve recuento histórico del recurso de queja, $v$. TAVOLARI (1999), pp. 3-7.
} 
bien desde sus inicios la casación se presentaba como un instrumento destinado a obtener una uniforme aplicación del Derecho en el país ${ }^{10}$, su efectividad se vio progresivamente reducida, sobre todo si consideramos la creciente importancia que adquirió en nuestro Derecho el mencionado recurso de queja, que permitía a las partes acceder al máximo tribunal para obtener una revisión de su causa a través de un mecanismo desformalizado, donde las funciones ejercidas por la Corte se acercaban muchísimo más a la posibilidad de revisión o de tercera instancia (e incluso, según se criticó en su oportunidad por la doctrina nacional, a un tribunal de equidad), que a la función clásica de garantizar la uniformidad en la interpretación judicial, propia de una Corte de Casación ${ }^{11}$.

Esta situación, absolutamente anómala desde una perspectiva comparada al decir del profesor TAVOLARI ${ }^{12}$, justificaría una de las más importantes reformas que nuestro ordenamiento procesal ha experimentado: nos referimos a la Ley No 19.374 de 1995, que vino a cambiar la relación existente entre estos dos recursos: a partir de esa fecha, el recurso de queja solamente procedería en aquellos casos en que no exista ningún otro recurso jurisdiccional que posibilite la revisión de las sentencias; mientras que la casación se vería liberada de algunas de sus formalidades de interposición, con miras a favorecer el desarrollo de una jurisprudencia consistente. Sin embargo, aun el modelo de casación después de la reforma de 1995 ha presentado deficiencias ${ }^{13}$.

La primera de ellas se expresa particularmente en el tipo de control formal que la Corte efectúa a propósito de su admisibilidad, aun por sobre el control prelimi-

\footnotetext{
${ }^{10}$ En este sentido, se señala en el Mensaje del Código de Procedimiento Civil que "La casación en el fondo introduce en nuestra legislación una novedad reclamada por las necesidades de dar uniforme aplicación a las leyes. Se ha limitado sólo a las sentencias de las Cortes de Alzada, como encargadas de dar la norma para el correcto funcionamiento de los tribunales inferiores".

${ }^{11}$ Esto por supuesto, si aceptamos que a través del recurso de casación en el fondo la Corte Suprema puede desarrollar funciones propias de una Corte de este tipo, circunstancia controvertida, sobre todo si consideramos los efectos que tiene sobre todo el sistema la posibilidad de dictación de una sentencia de reemplazo, cuestión que acerca nuestro modelo al de una tercera instancia. Sin embargo, debe notarse que el legislador nacional estaba desde un principio consciente de esta problemática, como bien lo refleja el Mensaje del Código de Procedimiento Civil al decir que "Aun cuando, para conservar a la casación su verdadero y elevado carácter, aconsejan muchos jurisconsultos limitar las funciones del tribunal a sólo la declaración que invalida el fallo reclamado, se ha creído preferible encomendarle también la resolución del asunto en que la casación recae, con el fin de evitar dilaciones y gastos a los litigantes, y una organización más vasta del tribunal a quien se encarga esta misión".

${ }^{12}$ Tavolari (1996), pp. 6-7.

${ }^{13}$ Según De la Fuente, entre las causas que han contribuido al desmedro de la función nomofiláctica de la casación se incluye el excesivo rigor formal con que el tribunal evaluaba los requisitos formales de interposición del recurso, la compleja y sofisticada posición de la Corte en relación a cuál era la norma infringida, el prácticamente nulo ejercicio de la facultad de actuar de oficio en esta materia, el funcionamiento de la Corte en salas, el amplio espectro del recurso de queja y el marcado positivismo formal que mostraba la Corte en su concepción del Derecho. De la Fuente Hernández, Nancy (2011). "El certiorari en el Proyecto de Código de Procedimiento Civil”. En: Justicia civil y comercial: Una reforma ¿Cercana?, LetURIA InFANTE, Francisco (Edit.), Santiago: LyD Editores, p. 376.
} 
nar sobre el mérito del recurso que permite el artículo 782 inciso $2^{\circ}$ del Código de Procedimiento Civil ${ }^{14}$. Sin embargo, pese al carácter amplio con que la Corte ejerce estas facultades ${ }^{15}$, las estadísticas de ingresos han ido en aumento desde el año $2000^{16}$, lo mismo que ocurre con las causas pendientes de fallo ${ }^{17}$. Aunque existen otras causas que permiten explicar estos aumentos -como podría ser un posible aumento en el número de recursos de protección de que deba conocer la Corte-, no deja de resultar preocupante este fenómeno ${ }^{18}$, sobre todo considerando lo que ha sido la evolución comparada que han experimentado otros máximos tribunales ${ }^{19}$, y la importancia que tiene un rápido conocimiento y fallo de los recursos, en el contexto del derecho a un proceso sin dilaciones ${ }^{20}$.

\footnotetext{
${ }^{14}$ Como destaca el profesor Tavolari, el rechazo in limine del recurso de casación en el fondo por falta de fundamentos supone un estudio primario del fondo del negocio, que se diferencia de otras cuestiones manifiestamente formales, como el que la resolución recurrida no sea de aquellas impugnables por este recurso, o el que el escrito en que interpone el recurso cumple o no con determinados contenidos, o no cuente con patrocinio de abogado, o haya sido interpuesto dentro de plazo. TAVOLARI (1996), p. 40.
}

${ }^{15}$ Según estudios efectuados por la profesora Israel durante el periodo 2000-2004, cerca de un tercio de los recursos de casación ingresados en ese lapso fueron desestimados por la Corte en base a razones formales, cifra que incorpora aquellos recursos declarados inadmisibles por manifiesta falta de fundamentos. ISRAEL López, Ruth (2006). "Control de admisibilidad del recurso de casación en materia civil años 2000-2004". Revista de Estudios de la Justicia, No 8, pp. 202-203. La forma como la Corte interpreta sus facultades ha sido criticada por el profesor Atria, para quien ésta ha llegado al extremo de usar las formalidades de interposición del recurso, como si le diesen un derecho subjetivo a rechazar el recurso, el cual miraría al interés de la Corte en tener una carga de trabajo limitada. ATRIA (2005), pp. 278-279. Este mismo fenómeno ha sido advertido en otros ordenamientos jurídicos, como lo consigna Nieva para el caso español. Nieva FENOLl, Jordi (2010). El Recurso de casación. Santiago: LegalPublishing, pp. 15-16.

${ }^{16}$ Así, mientras el año 2000 existieron 5.488 ingresos ante la Corte Suprema, esta cifra se había más que duplicado para el año 2011, en que se produjeron 12.713 ingresos.

${ }^{17}$ Que han aumentado de 3.465 el año 2000, a 4.345 el año 2010.

${ }^{18}$ En este sentido, señala el profesor Silva que "Hoy día resulta preocupante el nivel de causas pendientes de fallo por la Corte Suprema, en términos que al 31 de diciembre del año 2009 quedaron pendientes de ser resueltas 4.189 causas, a pesar de los ingentes esfuerzos de nuestros Magistrados. Más de la mitad de estas causas pendientes representan recursos de casación en el fondo pendientes (2.187). Está claro que no hay capacidad para resolver este colapso con los medios actuales, ni se visualiza que pueda haberlo en el futuro, al menos con los mismos medios". Silva Prado, José Pedro (2011). "Consideraciones sobre los fines de la casación civil y el recurso extraordinario en el proyecto de Código Procesal Civil chileno”. En: Justicia civil y comercial: Una reforma ¿Cercana?, LetURIA Infante, Francisco (Edit.), Santiago: LyD Editores, p. 390.

${ }^{19}$ Siendo quizás el paradigma de este fenómeno la inmensa Corte de Casación italiana.

${ }^{20}$ Adicionalmente, el que el máximo tribunal conozca y resuelva de un elevado número de recursos puede todavía generar un problema adicional, relacionado con el posible carácter variable, incoherente y hasta contradictorio que se puede esperar como consecuencia de la existencia de muchas decisiones emanadas de la misma Corte sobre un mismo punto. En este sentido, señala TARUFFo que "Existe, sin embargo, una conexión directa entre la fuerza del precedente y el hecho de que éste provenga de una corte que decide pocos casos, eventualmente disponiendo del poder de escoger cuales casos considera que sea oportuno decidir en el fondo. En sustancia, es más autorizado el precedente establecido por una corte que pronuncia pocas sentencias con la finalidad de establecer puntos de referencia para la decisión de casos idénticos o similes, y es menos autorizado el precedente que pertenece a un raudal formado por un número elevado de decisiones emitidas en la sola perspectiva de resolver cuestiones de derecho surgidas en los singulares casos específicos. Hay que considerar que la nomofilaquia que se 
Una segunda razón de importancia mira a la manera como este recurso desempeña su función de asegurar una correcta aplicación de la ley por parte de los tribunales nacionales, en términos de asegurar una interpretación uniforme de las disposiciones legales. En esta cuestión se revela particularmente en el fracaso del mecanismo último de unificación de jurisprudencia previsto por el legislador en 1995, que confería al Pleno de la Corte Suprema la facultad de conocer y resolver aquellos asuntos en los cuales la propia Corte haya sostenido con anterioridad interpretaciones diferentes de una misma norma legal (artículo 780 CPC), fracaso que se debe a su nula aplicación en la práctica ${ }^{21}$ y al hecho que, en el único caso en que recibió aplicación ${ }^{22}$, la decisión interpretativa del Pleno fue prontamente revertida por la Segunda Sala de la Corte ${ }^{23}$.

Cada uno de estos problemas mira a cuestiones diversas que pueden suscitarse con ocasión del recurso que será conocido por parte del máximo tribunal: así, mientras la primera de las dificultades señaladas mira a cuáles serán los criterios que permitirán a la Corte "seleccionar" los casos que serán por ella conocidos, la segunda mira a la forma de asegurar que el recurso pueda desarrollar su función nomofiláctica ${ }^{24}$. Estas dos materias serán comentadas, a propósito de la regulación propuesta por el Ejecutivo en el Proyecto actualmente en tramitación.

\section{La PROpuesta del EjeCutivo}

El Boletín No 8197-07 asume explícitamente desde su Mensaje que una de las reformas más profundas e importantes al sistema recursivo dice relación con

realiza a través del precedente resuelve un caso pasado, pero se trata de una decisión que se dirige hacia el futuro porque se propone como un modelo para decisiones sucesivas". TARUFFO, Michele (2007). “¿Una reforma a la casación civil?. En: Proceso Civil. Hacia una Nueva Justicia Civil De la Oliva Santos, Andrés y Palomo VéLEZ, Diego (Coord.), Santiago: Editorial Jurídica de Chile, pp. 517-518.

${ }^{21}$ Por lo demás, no es difícil identificar ciertos problemas relacionados con la creación de incentivos para el uso de herramienta: según el artículo 780 del Código de Procedimiento Civil quien debe solicitar que la causa sea resuelta por el Pleno de la Corte Suprema es el propio recurrente, acreditando que el máximo tribunal del país ha sostenido interpretaciones contradictorias sobre la materia de derecho objeto del recurso, lo que equivale, en la práctica, a imponerle la carga de sacrificar su interés privado, reconociendo que la tesis que postula sobre el caso es controvertida en la jurisprudencia nacional, con miras a satisfacer un interés público, la uniforme aplicación del derecho.

${ }^{22}$ Corte Suprema, 21 de enero de 2013, Rol No 10665-2011.

${ }^{23}$ Corte Suprema, 4 de septiembre de 2013, Rol No 3841-2012.

${ }^{24}$ Sobre este punto puede desarrollarse todavía una segunda discusión: ¿Cuál es la forma de nomofilaquia que será preferida por el ordenamiento? ¿Se tratará de una nomofilaquia analítica y total, destinada a realizarse por medio del control amplio de las decisiones pronunciadas por los tribunales inferiores, o de una nomofilaquia expresada a través de grandes decisiones? Como señala TARUFFo, la garantía de legalidad admite una lectura objetiva y una subjetiva, estando esta última centrada en torno a la garantía del ciudadano en contra de las violaciones de ley, siendo protegidos sus derechos subjetivos. Precisamente, del desarrollo de uno u otro modelo dependerá el equilibrio que en cada sistema se produzca entre el ius litigatoris y el ius constitutionis y la posición que tendrá la jurisprudencia de la Corte Suprema dentro de las fuentes del Derecho. TARUfFo (2006), p. 23. 
la sustitución del actual recurso de casación en el fondo por el nuevo recurso extraordinario, con miras a fortalecer el rol de la Corte Suprema como máximo tribunal de la República, encargado de preservar los derechos fundamentales y de dar coherencia y unidad a los criterios de decisión de los tribunales del país, tomando un decidido partido por la primacía del interés general como criterio que justifica la intervención de la Corte, cuestión que se refleja particularmente en la introducción de criterios ampliamente discrecionales en la admisibilidad del recurso. En este contexto, como bien ha destacado el profesor SiLVA, no es de extrañar que el recurso extraordinario se justificare en su vocación pública de uniformar la doctrina jurisprudencial, la cual actuaría en beneficio de cautelar un bien preciado por el Derecho, cual es la certeza y seguridad jurídicas derivadas de la aplicación coherente y sistemática de una misma interpretación jurídica, siendo para el justiciable una garantía de igualdad ante la ley ${ }^{25}$.

Ahora bien, aunque el Proyecto no va tan lejos como para reconocer expresamente la existencia de un certiorari ${ }^{26}$, como sí lo hacían proyectos anteriores ${ }^{27}$, sí ha establecido un criterio de selección amplio, que permite a la Sala respectiva de la Corte decidir, soberanamente según se señala en el Mensaje, si concurre un interés general en el conocimiento del recurso; estimándose concurrir este interés solamente cuando se hubiere infringido en forma esencial, en la sentencia o en el procedimiento, un derecho fundamental; o en caso que la Corte considere pertinente fijar, uniformar, aclarar o modificar, una doctrina jurisprudencial ${ }^{28}$.

La regulación propuesta por el Ejecutivo resulta potencialmente problemática, desde el momento que pasa a reconocer una amplia discreción a la Corte para efecto de definir cuáles serán las materias que entrará a conocer, con prescinden-

\footnotetext{
${ }^{25}$ SilVA (2011), p. 386.

${ }^{26}$ Según señala DELGADO “La admisibilidad del recurso también se ha visto notablemente favorecida. Esencialmente, las previsiones son las mismas, sin embargo, el nuevo orden sistemático confiere mucha mayor claridad pese a que sigue resultando confuso saber que se ha de entender por requisitos formales. Pero, sin duda, el mayor acierto ha sido eliminar el certiorari. En el actual Proyecto se conserva el mecanismo de selección discrecional pero en un lenguaje más comprensible y con un desarrollo más detallado que permite a los litigantes conocer qué debemos entender comprendido en este concepto". Delgado CASTRO, Jordi (2012). "El recurso extraordinario en el Proyecto de Código Procesal Civil”. Ius et Praxis, año 18, No 2, p. 142.

${ }^{27}$ Según se establecía en el Proyecto de Código Procesal Civil de 2009 (Boletín 6567-07), la Corte Suprema, aun en circunstancias de haberse cumplido por el recurrente las requisitos sujetos a control de admisibilidad de acuerdo al artículo 358, contaba expresamente con el certiorari, pudiendo seleccionar para su conocimiento sólo aquellos casos que revistan interés público a juicio de a lo menos tres de sus ministros (artículo 359).

${ }^{28}$ Artículo 409. "Interés general. La Corte Suprema determinará avocarse al conocimiento del asunto cuando la mayoría de los miembros de la sala respectiva estime que concurre un interés general que haga necesaria su intervención.

Sólo podrá estimarse que concurre un interés general para avocarse al conocimiento del asunto en los siguientes casos:

a) Cuando se hubiere infringido en forma esencial, en la sentencia o en el procedimiento del cual ella emanare, un derecho o garantía fundamental contemplado en la Constitución Política de la República o en los tratados internacionales ratificados por Chile y que se encuentren vigentes $y$;

b) En caso que considere pertinente fijar, uniformar, aclarar o modificar, una doctrina jurisprudencial'.
} 
cia del interés privado que se haya visto comprometido en la decisión del asunto por parte de la Corte de Apelaciones, en lo que supone un nuevo equilibrio que reemplaza al fijado por el Tribunal Constitucional en su Sentencia de 1 de febrero de $1995^{29}$ : en efecto, con ocasión de esta decisión, el citado Tribunal declaró inconstitucional la segunda parte del nuevo artículo 782 del Código de Procedimiento Civil, en los términos en que había sido aprobado durante la tramitación de la Ley No 19.374, el cual disponía que "La misma sala, aun cuando se reúnan los requisitos establecidos en el inciso precedente, podrá rechazarlo [el recurso de casación en el fondo] de inmediato si, en opinión unánime de sus integrantes, adolece de manifiesta falta de fundamento o carece de relevancia jurídica para la adecuada interpretación y aplicación del derecho"30, por considerar que el que el recurso carezca de relevancia jurídica no dice relación alguna con la pretensión deducida por el recurrente, sino que solamente mira a ciertas funciones residuales en la casación, como son el desarrollo de doctrinas o jurisprudencias, las cuales resultan ajenas a los deberes propios de los tribunales (resolver conflictos de relevancia jurídica) y pugnan con el principio de inexcusabilidad. Como se puede apreciar, una revisión de esta materia puede en consecuencia implicar una reforma en la Constitución, a menos que los nuevos argumentos presentados al Tribunal Constitucional sean lo suficientemente persuasivos como para hacerlo revisar su jurisprudencia anterior.

Sin embargo, este problema constitucional que debe ser resuelto por el legislador es solamente una expresión del problema de fondo: ¿Cuál es la función que corresponderá desarrollar a la Corte? ¿'Se tratará de una Corte llamada a tutelar la correcta aplicación del derecho, en el caso concreto, o de una Corte que participe junto al legislador en la creación del derecho? Cuando pensamos en nuestra Corte Suprema, ¿pensamos en una Corte que actúa corrigiendo errores en que han incurrido otros tribunales, o en una Corte que actúa "tomando partido" en temas que plantean grandes disputas doctrinarias? ${ }^{31}$ En gran medida, un modelo de Corte como el que subyace a la regulación contenida en el Proyecto resulta contradictorio tanto con la función que hasta el día de hoy ha desarrollado la Corte Suprema resolviendo conflictos, como con la concepción que la propia Corte tiene de sí misma. Piénsese, por vía solamente ejemplar, hasta qué punto prácticas interpretativas como las sostenidas por la Corte Suprema a propósito de las inscripciones de papel o de los límites de las reglas del precario, donde existe ciertamente una consideración hacia la justicia del caso concreto en los límites de la aplicación de la ley, podrían resultar compatibles con un modelo de Corte llamada a decidir, no mirando a la causa que se le ha presentado a su conocimiento, sino que a la correcta y uniforme aplicación del derecho en los casos venideros. Finalmente, esta misma

\footnotetext{
${ }^{29}$ Sentencia Tribunal Constitucional, Rol No 205-1995, 1 de febrero de 1995.

${ }^{30} \mathrm{El}$ destacado es nuestro.

${ }^{31}$ La distinción está en Maturana (2012), p. 450.
} 
definición tiene una repercusión política importante, sobre todo en circunstancias en que una de las grandes polémicas que se ha producido en los últimos años dice relación con el activismo judicial y la relación existente entre la Corte Suprema y los restantes poderes del Estado, desde el momento que, como bien ha destacado el profesor ATRIA, una Corte con un poder discrecional para fijar cuáles son las materias de las cuales conocerá es un tribunal que puede fijar su propia agenda ${ }^{32}$.

Desde una perspectiva procesal, la regulación de la admisibilidad del recurso extraordinario presenta también ciertas complicaciones, las cuales están relacionadas con el órgano llamado a realizar este control y con la forma en que éste se efectúa. En lo que concierne al órgano, en el Proyecto el control quedaba radicado exclusivamente en una Sala de la Corte Suprema (artículo 410 PCPC), cuestión que si bien puede parecer una decisión acorde con una visión moderna del Derecho procesal ${ }^{33}$, creemos que obedece más bien a una decisión política, destinada a excluir a las Cortes de Apelaciones de cualquier tipo de control sobre el recurso, con lo que se destaca el hecho que resulta ampliamente discrecional para la Corte Suprema avocarse a su conocimiento. Por otra parte, en lo que se refiere a la forma en que se realiza este control, si bien debe destacarse que el Proyecto reconocía a la Corte la posibilidad de dar traslado al recurrido, si lo estimare pertinente, para que en el plazo de diez días haga valer las razones por las cuales, en su concepto, no se justifica que la Corte se avoque al conocimiento del asunto (artículo 410 inciso $3^{\circ}$ PCPC), puede ocurrir que esta facultad por sí sola resultare insuficiente para efectos de garantizar la debida publicidad en el proceso, atendido que es una decisión que se adoptará sin previa vista de la causa, formándose los ministros integrantes de la Sala una impresión sobre el mérito de la causa de manera mediata, pasando los relatores a ocupar una posición central en el sistema. Los peligros que implica esta situación se ven aumentados, si consideramos que tampoco existía en el Proyecto una regulación específica en relación con los requerimientos de fundamentación que debe satisfacer la resolución que declara inadmisible el recurso por no existir un interés general, en circunstancias que esta decisión debería insertarse en un sistema de selección que resguarde el máximo de transparencia, donde su concesión o denegación sea fundamentada, a fin que pueda estar sujeta a un control público y que permita a los operadores saber cuáles casos pueden ser planteados a la Corte con posibilidades de éxito ${ }^{34}$.

Finalmente, en lo que respecta a la perspectiva orgánica, debe tenerse presente que quien resolverá la admisibilidad del recurso en razón del interés general será

\footnotetext{
${ }^{32}$ Atria (2005), p. 227.

${ }^{33}$ En este sentido, señala DELGADO que "El tener que interponer el recurso directamente ante el órgano que ha de conocer permite evitar una revisión de requisitos formales y, quizás lo más importante, que dos órganos jurisdiccionales de los llamados Tribunales Superiores (que probablemente indica que jerárquicamente tienen mayor relevancia que otros) deban revisar los mismos aspectos dos veces". Delgado (2012), p. 130.

${ }^{34}$ De la Fuente (2011), p. 381.
}

Revista de Derecho - Escuela de Postgrado No 5, julio 2014

Páginas 393 - 406

ISSN $0719-1731$ 
una Sala de la Corte, sin que exista una posibilidad ulterior de revisión por parte del Pleno, de manera que la conformación de la Sala respectiva (y particularmente, las sensibilidades de los ministros que la integrarán) pasará a ser una cuestión crucial al momento que la Corte defina cuáles serán las materias a cuyo conocimiento se avocará. Por esta misma razón, pareciera que si el objetivo de la reforma es contribuir a la uniformidad de la aplicación del Derecho, resulta urgente introducir las modificaciones destinadas a eliminar la figura de los abogados integrantes, cuya presencia eventual puede atentar en contra de los fines de uniformidad que persigue el recurso.

Ahora bien, en lo que concierne a las causales que permiten calificar la existencia de un interés general, debemos destacar que ésta era una de las materias que más problemas presentaba en la regulación propuesta en el Proyecto original. Como se señaló anteriormente, según el artículo 409 PCPC la Sala podía estimar que concurría un interés general que hiciera necesaria la intervención de la Corte si la resolución impugnada infringiere de manera esencial un derecho reconocido en la Constitución o en un Tratado Internacional, o en caso que la invalidación de la resolución recurrida fuere necesaria, a fin de fijar, uniformar, aclarar o modificar una doctrina jurisprudencial. Cada una de estas causales merece comentarios por separado.

La introducción de la primera causal señalada resultaba especialmente problemática. En primer término, porque desdibuja las competencias delimitadas por la reforma constitucional de 2005 entre la Corte Suprema, máximo órgano del Poder Judicial y quien debe efectuar un control conforme al Derecho común, y el Tribunal Constitucional, jurisdicción especializada a quien corresponde el control de constitucionalidad. Como expresión de este hecho, debe considerarse que en el Derecho comparado, una función análoga a aquella que el legislador pretendía atribuir a la Corte Suprema por vía del recurso extraordinario es desarrollada por el recurso de amparo (España y Alemania ${ }^{35}$ ), el cual es conocido por los tribunales constitucionales. En segundo término, porque sin haber antes discutido orgánicamente la forma en que se integrará el "control de convencionalidad" que impone en nuestro ordenamiento la vigencia de la Convención Americana de Derechos Humanos, lo radicaba directamente en la Corte Suprema ${ }^{36}$. Finalmente, porque no

\footnotetext{
${ }^{35}$ En este sentido, destacada STÜRnER que en contra de las sentencias del Superior Tribunal Federal (Bundesgerichthof) se puede interponer una queja constitucional, en la medida que se trate de sentencias viciadas gravemente, que impliquen una violación de los derechos fundamentales, cuestión que ha implicado que el Tribunal Constitucional Federal (Bundesverfassungsgericht) haya ido asumiendo una gran influencia en relación a la jurisprudencia civil, siendo designado frecuentemente como una instancia de súper revisión. STÜNER, Rolf (2013). “Recursos en el proceso civil alemán”. En: Derecho Procesal Civil Comparado: Homenaje a RolfStürner, Pérez Ragone, Álvaro y Tavolari Goycoolea, Pía (Coord.), Santiago: LegalPublishing, p. 102.

${ }^{36}$ Una defensa de la atribución de esta competencia a la Corte Suprema puede encontrarse en MATURANA (2012), pp. 432-433, 436-437 y 456. Según señala el profesor Maturana, la Corte Suprema no solo debe tener competencia para uniformar la jurisprudencia sobre el Derecho interno, sino también para velar por el respeto y promoción de los derechos fundamentales, pudiendo de esta forma crear estándares a su
} 
debemos olvidar que en esta materia estamos hablando de litigios que se suscitan entre particulares, sean de naturaleza civil o comercial, conflictos en los cuales la aplicación directa de la normativa constitucional puede resultar compleja, atendida la textura abierta y alta carga valorativa de sus disposiciones, cuestiones que pueden afectar la correcta comprensión de las instituciones del Derecho privado a partir de sus propias categorías. La tensión existente entre la forma en que se comprende la propiedad para efectos del ejercicio de las acciones reales y el supuesto nacimiento de un nuevo concepto "constitucional" de propiedad, desarrollado con ocasión de los recursos de protección, es una buena prueba de ello.

Por su parte, la relación entre la primera y la segunda causal da cuenta de un problema más profundo ¿Cuál será la posición de la ley en el control que efectuará la Corte Suprema? Ninguna de las señaladas causales la contemplaba específicamente como un parámetro de control: la primera, porque establecía una suerte de control de la sentencia desde una perspectiva supralegal; la segunda, porque entiende que la invalidación de la resolución recurrida no procede ante la sola infracción de la ley, requiriendo además que ésta fuere necesaria a fin de fijar, uniformar, aclarar o modificar una doctrina jurisprudencial, todo lo cual afectaba la relación entre la ley y la jurisprudencia en cuanto fuentes del Derecho. Si bien puede pensarse, como lo hace Delgado, que la lectura integrada de los artículos 408 y 409 del Proyecto parece indicar que se exige haber infringido un derecho o garantía, o bien algún aspecto que merece sentar doctrina jurisprudencial, de manera que al menos indirectamente sería también requisito el haber infringido la ley ${ }^{37}$, parece conveniente invertir los términos de la causal, a fin de establecer como factor central para definir la procedencia del recurso la uniforme aplicación de la ley, siendo la existencia de doctrinas jurisprudenciales contradictorias elementos para juzgar la existencia de divergencias que ameriten un pronunciamiento por el máximo tribunal. Sobre este punto, aunque se haya argumentado persuasivamente que la reforma no implica una modificación del sistema de fuentes ${ }^{38}$, parece indispensable mantener a la ley como el parámetro de control último de las decisiones jurisdiccionales, a fin de poder hacer realidad la nomofilaquia en cuanto fundamento último del recurso ${ }^{39}$ y de mantener una relación equilibrada en el Poder Judicial y el Poder Legislativo.

respecto que sean coincidentes con los que emanan de la jurisprudencia de los tribunales supranacionales, convirtiéndose de esta forma en la última garante del principio de convencionalidad, sin que se pueda entender agotada la vía interna para acudir ante tribunales internacionales si no se ha requerido la intervención de nuestra Corte Suprema.

${ }^{37}$ NieVAS (2010), p. 63.

${ }^{38} v$. Bravo Hurtado, Pablo (2013). "Hacia los precedentes en Chile. Reforma procesal civil y fuentes del Derecho". Revista Chilena de Derecho, Vol. 40, No 2, pp. 549-576.

${ }^{39}$ Precisamente, una de las cuestiones más problemáticas de esta causal es el posible cambio en la práctica interpretativa de la Corte Suprema que pueda suponer su introducción en nuestro ordenamiento, donde la Corte pase de abocarse a revisar cómo se interpretó la ley, a revisar cómo se interpretó la jurisprudencia. Bravo (2013), p. 567. Por lo demás, un cambio de esta envergadura no puede desatender lo que ha sido 
Precisamente, como puede apreciarse de todo lo expuesto, el recurso extraordinario, reconociendo las dificultades que presenta la actual regulación de la casación para satisfacer los fines previstos en su diseño original, plantea soluciones que, en su afán de privilegiar el desarrollo del interés público y de crear las condiciones para el nacimiento de una cultura del precedente, sacrificaba completamente el interés de las partes litigantes: no importando cuán errónea pudiera haber sido la aplicación del Derecho realizada en una sentencia, la parte agraviada con su dictación solamente podía obtener su impugnación si la mayoría de los miembros de la Sala consideraban que concurría un interés general que hiciera necesaria su intervención. En este sentido, no podemos desatender las certeras críticas del profesor NIEVAS, al decir que "No creo que pueda afirmarse válidamente que las leyes existen para la sociedad, reiterando aquel viejo aforismo ubi societas ibi ius, $y$ al mismo tiempo mantener a renglón seguido que el tribunal de casación, el principal custodio de las leyes, no puede perder su tiempo en ocuparse de los asuntos del ciudadano. La contradictio in terminis me temo que es patente, pero por más evidente que resulta, no por ello cejan algunos tribunales de casación, algunos legisladores y en ocasiones la propia doctrina, en su empleo de excluir que cuando hablamos de casación estemos tomando en consideración un tema profundamente social' 40 . Es este equilibrio entre estos dos intereses en juego en la definición de los fines de recurso extraordinario el que debe ser objeto de una reflexión durante la segunda etapa de tramitación parlamentaria.

\section{LA DISCUSIÓN DE FONDO: SOBRE LA NECESIDAD DE UNA REFORMA ORGÁNICA}

En este breve comentario se ha pretendido plantear de una manera resumida los principales problemas que deben ser resueltos por el legislador al momento de definir cuál será el recurso que permita a las partes acceder al máximo tribunal del país a fin de obtener una revisión de su caso, poniendo especial énfasis en el hecho que se trata de una reforma que excede con creces el marco de lo meramente procedimental, para situarse en un plano más político, que dice relación con el modelo de Corte Suprema que deseamos para nuestro país. En este contexto, resulta particularmente llamativo el hecho que, si bien se presenta como una reforma que

\footnotetext{
la experiencia de otras reformas procesales habidas en el país. En este sentido, señalan Delgado y Díaz que "Un segundo problema con el que se enfrentará la aplicación del recurso extraordinario es la falta de una cultura judicial tendiente a respetar las interpretaciones de la Corte Suprema cuando adopta una decisión en unificación de jurisprudencia. En este sentido es posible citar lo acaecido con el recurso de unificación de jurisprudencia laboral. Esto se debe a que ambos recursos presentan coincidencia en sus fines y en sus causales de procedencia". Delgado Castro, Jordi y Díaz García, Iván (2011). "La unificación de jurisprudencia pretendida por el recurso extraordinario. Ventajas y problemas”. Revista de Derecho de la Universidad Católica del Norte, año 18, No 2, p. 287.

${ }^{40}$ Delgado (2012), p. 131.
} 
está destinada a destacar la posición de la Corte en cuanto máximo tribunal del país e intérprete último de la ley, lo haga por una vía que implica reducir drásticamente las controversias sobre las que ella podrá pronunciarse, todo esto de una manera que incluso implica redefinir el rol que a la propia Corte le corresponde desarrollar en nuestro ordenamiento. Aunque resulte paradójico, puede suceder que la reforma procesal nos lleve a tener una Corte Suprema que se pronuncie sólo en los grandes casos, pero que deje de hacer justicia en todas las violaciones de ley que impliquen "solamente" la afectación de los derechos subjetivos de los justiciables.

Ahora bien, como queda de manifiesto de todo lo expuesto, una reformulación sobre las funciones que corresponde desarrollar a la Corte Suprema no puede dejar de implicar una revisión de sus otras competencias. ¿Es compatible con el modelo de Corte que se quiere desarrollar con ocasión del recurso extraordinario el que ella deba seguir conociendo de un masivo número de apelaciones de recursos de protección? ¿Cómo se conjugan en este esquema los recursos de nulidad en materia penal y el recurso de unificación de jurisprudencia laboral? O más importante todavía ¿Cómo justificar en este esquema la subsistencia del recurso de queja, mecanismo de control que aparece absolutamente contrario a las exigencias institucionales que implica el reconocimiento de una judicatura independiente, atendido lo impropio que resulta obtener la revisión de una decisión jurisdiccional a través de un mecanismo disciplinario y jerárquico? Todas estas son materias que deben ser objeto de discusión, a fin que la reforma no cree incoherencias sistémicas en lo que se refiere a la posición institucional de la Corte y las funciones que le son atribuidas.

Finalmente, en lo que se refiere a los aspectos procesales, parece necesario revisar las causales del recurso, reemplazando las causales previstas por el artículo 409 PCPC por otras que expresen de manera menos problemática lo que deben ser las funciones de la Corte; y mejorar el procedimiento de control de la admisibilidad del recurso, a fin de evitar que en la cúspide del sistema se vea comprometida la publicidad del proceso y la debida fundamentación de las sentencias.

Por todas estas razones, resulta especialmente bienvenida la apertura a la discusión que se ha producido con la decisión de la Cámara de rechazar esta parte del Proyecto, siendo esperable que todos quienes están por mejorar nuestro Derecho participen de ella. 